\title{
Review
}

\section{Landmark Trials in Renal Cancer}

\author{
Ulka Vaishampayan* \\ Karmanos Cancer Institute, Wayne State University, Detroit, MI, USA
}

\begin{abstract}
The therapy of kidney cancer has made multiple major advances. Eleven agents are now approved by FDA for treatment of metastatic RCC and one agent is approved for adjuvant therapy for localized high risk disease post nephrectomy. In addition the trials addressing the role of surgery also represent major strides in therapy. All these advances in RCC therapeutics have occurred through clinical trials. This paper is a summary of landmark trials that have been critical in the therapeutic development journey in advancing the care and improving outcomes in kidney cancer. The front line therapies are summarized starting with immunotherapy with high dose interleukin-2 to targeted therapies such as bevacizumab (monoclonal antibody), receptor tyrosine kinases such as sorafenib, sunitinib, and pazopanib and MTOR inhibitors lke temsirolimus in the front line setting. Recently the combinations of ipilimumab and nivolumab as well as bevacizumab and atezolizumab have demonstrated promising efficacy in metastatic disease and these regimens are likely to receive FDA approval. In second line and beyond, therapies such as everolimus, nivolumab, lenvatinib+ everolimus and Cabozantinib have proven benefit. Adjuvant post nephrectomy trials have been conducted with conflicting results. Majority have shonwn lack of benefit, however one study conducted in T3/T4/N1 disease revealed statistically significant disease free survival favoring ajuvant sunitinib therapy leading to FDA approval. This paper summarizes the data from the reported trials and discusses recent developments in RCC therapeutics.
\end{abstract}

\section{INTRODUCTION}

Kidney cancer has evolved from a disease with no widely applicable standard therapy, to one with a plethora of systemic therapies that have demonstrated remarkable response rates and durable remissions. Every advance in clinical management of advanced renal cancer (RCC) has occurred through clinical trials. Successful implementation of clinical trials is the main conduit for drug development in most diseases. In kidney cancer over the past decade this has been well proven and giant steps forward have occurred due to mechanistically driven rational clinical trials in RCC. Previously a disease

\footnotetext{
*Correspondence to: Ulka Vaishampayan, MD, Department of Oncology, Karmanos Cancer Institute, Wayne State University, Karmanos Cancer Center 4100 John R Detroit, MI 48201, USA. Tel.: +1 3135768715; Fax: +1 313576 8487; E-mail: vaishamu@karmanos.org.
}

only treated with cytokines, discoveries of mutations impacting the von Hippel-Landau (VHL) tumor suppressor gene leading to increased expression of vascular endothelial growth factor (VEGF) and hepatocyte growth factor (MET) and of deregulations in PI3K/AKT/mammalian target of rapamycin (mTOR) pathway, resulting in tumor angiogenesis, cell proliferation and tumor growth have led to the development of numerous targeted therapies. These have led to Food and Drug Administration (FDA) approval of a total of nine targeted therapies and one immunotherapy since 2005. These include vascular endothelial growth factors (VEGFR) tyrosine kinase inhibitors (sunitinib, pazopanib, axitinib, sorafenib, and lenvatinib), monoclonal antibody targeting VEGF-A (bevacizumab), mTOR inhibitors (temsirolimus and everolimus), and a MET and VEGF inhibitor,, cabozantinib. Recently the combinations such as ipilimumab and nivolumab or 
bevacizumab and atezolizumab have shown promising efficacy and will likely cause a paradigm shift in frontline RCC management. With numerous therapies becoming available rapidly the next wave of clinical trials will need to address patient populations not eligible for previous clinical trials, optimal sequencing of agents, and biomarkers that would guide therapeutic selection.

\section{Adjuvant therapy landmark trials [Table 1]}

Initially immune therapy such as high dose interleukin-2 and interferon were tested in the adjuvant setting and no benefit was noted over surveillance alone [1,2]. Once the anti-VEGF therapies were well established in the metastatic setting, adjuvant studies were conducted in kidney cancer post nephrectomy. The first and largest trial was conducted by Eastern Cooperative Oncology Group (ECOG 2805) randomizing patients to placebo or sorafenib or sunitinib [3]. The study results revealed no difference in disease free survival (DFS)and OS and concluded that there was no role for adjuvant therapy in localized kidney cancer post nephrectomy. Recently the STRAC study results comparing sunitinib versus placebo in a high risk kidney cancer patient population reported a statistically significant PFS benefit favoring the sunitinib arm [4]. The patients with high risk disease per the University of California Los Angeles Integrated Staging System (UISS) were eligible for the study. The median DFS was 6.8 years with adjuvant sunitinib therapy and 5.6 months with placebo (Hazard ratio of 0.76 , $p=0.03$ ) and led to the FDA approval of sunitinib [https://www.fda.gov/NewsEvents/Newsroom/Press Announcements/ucm585657.htm]. However the adverse event profile of sunitinib requires careful consideration with a $48.4 \%$ and $12.1 \%$ incidence of grades 3 and 4 toxicties. The adjuvant pazopanib versus placebo trial randomized 1538 patients andshowed a lack of significant difference in the pazopnib $600 \mathrm{mg}$ daily arm $(\mathrm{HR}=0.862, p=0.165)$ [5]. A metaanalysis of adjuvant therapy trials suggests only a modest concordance between the endpoints and raises the concern of using DFS as a surrogate for OS [6] An established tumor microenvironment is likely to be required for antivascular agents to be effective and hence the improvement in remission rates was negligible in majority of patients in the adjuvant setting. The adjuvant therapy data indicates that adjuvant anti-VEGF therapy has limited utility in localized kidney cancer and hence currently open clinical trials should be supported. The current evidence warrants a balanced discussion of risk benefit ratio for adjuvant sunitinib in high risk kidney cancer (T3, T4 or N1 stage) post nephrectomy An adjuvant study of everolimus versus placebo (EVEREST trial/NCT01120249) led by the Southwest oncology Group has completed accrual and results are awaited. Results of studies testing adjuvant sorafenib and axitinib are also pending. A cooperative group trial of adjuvant pazopanib in the highest risk subgroup of metastatic resected RCC patients has recently completed accrual and results are awaited.

With the advent of PD-1 inhibitors, studies that are testing these in the perioperative setting are ongoing. PROSPER RCC [NCT03055013] is a trial evaluating neoadjuvant and adjuvant nivolumab as compared to nephrectomy alone. A randomized double blind study with adjuvant atezolizumab or placebo is also currently ongoing [NCT03024996]. Another adjuvant trial is randomizing post nephrectomy. $\geq \mathrm{T} 2$ kidney cancer to pembrolizumab or placebo with disease free survival as the primary endpoint [NCT03142334].

\section{Cytokine trials}

In 1992, high-dose interleukin-2 (HDIL-2) obtained FDA approval for first-line treatment of mRCC after preliminary data showed an overall response rate (ORR) of $15 \%$ including $5 \%$ complete response (CR). This landmark trial reported by Fyfe et al. noted the long term remission rates of the small proportion of responders in patients metastatic RCC treated with HDIL-2 [7]. A follow-up study reported $7 \% \mathrm{CR}$ with a noteworthy median duration of response of at least 80 months. Now there is a contemporary study that has evaluated the response rates (RR), progression free survival (PFS) and overall survival (OS) However given dose-limiting toxicities (DLTs), inclusion criteria requiring excellent performance status and adequate organ function, IL-2 remains a therapeutic option for a chosen few patients with advanced RCC [8]. In an attempt to decrease the acute treatment-related toxicity, Yang et al. compared high and low-dose IL-2, but unfortunately, ORR was greater in the high-dose arm $(21 \%$ vs. $13 \%, p=0.048)$ [9]. Additionally, analysis from a prospective cohort called the SELECT trial [10], and a retrospective cohort trial called PROCLAIM suggest that the contemporary response rate with HDIL-2 is $25 \%$ and $17 \%$, and OS benefit extends to intermediate risk patients and favorable risk patients [11]. 
Table 1

Adjuvant therapy trials

\begin{tabular}{|c|c|c|c|c|}
\hline Study [Ref] & Therapy & Patients & DFS & OS \\
\hline \multirow[t]{3}{*}{ ASSURE [3] } & Sunitinib & 647 & $\begin{array}{l}\text { Median5.8 years } \\
\quad(\mathrm{HR}=1.02) P=0.8038\end{array}$ & $\mathrm{HR}=1.17 P=0.17$ \\
\hline & Sorafenib & 649 & $\begin{array}{l}\text { Median } 6.1 \text { years } \\
\quad(\mathrm{HR}=0.97)\end{array}$ & \multirow[t]{2}{*}{$\mathrm{HR}=0.98 P=0.85$} \\
\hline & Placebo & 647 & $\begin{array}{c}\text { Median } 6.6 \text { years } \\
P=0.7184\end{array}$ & \\
\hline \multirow{7}{*}{$\begin{array}{l}\text { STRAC [4] } \\
\text { All Higher Risk per } \\
\text { UISS T3 with high } \\
\text { grade Fuhrman } \geq 2 \text { and } \\
\text { PS } \geq 1 \text { T4 or N1 }\end{array}$} & \multirow{7}{*}{$\begin{array}{l}\text { Sunitinib Vs Placebo } \\
\text { Sunitinib Vs Placebo }\end{array}$} & Total: 615 & & \multirow{5}{*}{$\mathrm{HR}=1.014 P=0.938$} \\
\hline & & 306 pts & & \\
\hline & & \multirow{5}{*}{$\begin{array}{l}309 \text { pts } \\
194 \\
194\end{array}$} & Median 6.8 years 5.6 & \\
\hline & & & years $\mathrm{HR}=0.76$ & \\
\hline & & & $P=0.04$ & \\
\hline & & & Median 6.2 years & Not reported \\
\hline & & & $\begin{array}{l}\text { Median } 4.0 \text { years } \\
\quad H R=0.74 P=0.04\end{array}$ & \\
\hline \multirow[t]{6}{*}{ PROTECT [5] } & Primary analysis & Total: 1134 & & \multirow{4}{*}{$\mathrm{HR}=0.791 P=0.1566$} \\
\hline & Pazopanib (ITT)600 mg & 571 & & \\
\hline & doseVs Placebo All & 564 & $\mathrm{HR}=0.862 P=0.1649$ & \\
\hline & patients (ITT) & Total: 1538 & & \\
\hline & Pazopanib Vs Placebo & 769 & Median not attained & \multirow[t]{2}{*}{$\mathrm{HR}=0.823 P=0.1570$} \\
\hline & & 769 & $\mathrm{HR}=0.802 P=0.0126$ & \\
\hline
\end{tabular}

\section{VEGF TARGETED THERAPIES}

\section{Landmark trials with anti-VEGF therapies in metastatic RCC}

Understanding of VHL gene mutations leading to induction of angiogenic protein vascular endothelial growth factor (VEGF), targeted therapies with tyrosine kinase inhibitors (VEGF-TKIs) were developed. VEGF-TKIs currently used for mRCC include sunitinib, sorafenib, pazopanib, axitinib, cabozantinib and lenvatinib [Table 2, 12-18]. Similarly, bevacizumab is a monoclonal antibody directed against the VEGF receptor [19, 20]. For over a decade, cytokines were the only approved treatment for mRCC. In 2005, sorafenib changed this paradigm with the TARGET study showing improvement in PFS versus placebo in the second-line setting after cytokine therapy (5.5 vs. 2.8 months, $p<0.01$ ) [12]. Shortly thereafter, a landmark study by Motzer et. al showed improved PFS with sunitinib compared to interferon in the first-line setting (11.0 vs 5.0 months, $p<0.001)$ [13]. The following year, the AVOREN Trial investigators published a comparison of bevacizumab and interferon in combination versus interferon monotherapy. Again, the results nearly doubled the PFS of the comparator arm (10.2 vs. 5.4 months, $p=0.0001$ ) [19]. CALGB 90206 was a cooperative group trial conducted in the US evaluating the same arms and reported improvement in
PFS also favoring the bevacizumab and interferon combination [20]. [Two years later, pazopanib was used in previously untreated patient and those who had progressed after cytokines in a phase 3 study [14]. Compared to placebo, there was a 5 month improvement in median PFS (9.2 vs. 4.2 months, $p<0.0001)$. Both pazopanib and bevacizumab in combination with interferon gained FDA approval in 2009 (Table 2). The COMPARZ trial randomized patients with advanced RCC to receive sunitinib or pazopanib in a double blind fashion [15]. The results demonstrated that the efficacy of pazopanib was noninferior to sunitinib, and the toxicity profiles varied with increased incidence of hepatic dysfunction in the pazopanib arm and higher incidence of diarrhea and hypertension in the sunitinib arm.

Since that time, no other agent has obtained approval in the first-line therapy setting. However, results of a recent study (CABOSUN) have led to the FDA approval of Cabozantinib for front line indication [21]. Cabozantinib is a small molecule inhibitor targeting multiple tyrosine kinases including VEGF receptor-2 (VEGFR-2), MET and AXL has undergone clinical trial evaluation. The CABOSUN trial compared cabozantinib to sunitinib in previously untreated mRCC patients with poor and intermediate prognosis per International Metastatic Renal Cell Carcinoma Database Consortium (IMDC) criteria [22]. Results showed a statistically significant improvement in PFS (Median 8.2 vs. 5.6 months), 
Table 2

Anti-VEGF therapy based landmark trials in RCC

\begin{tabular}{|c|c|c|c|c|}
\hline Study [Ref] & Therapy & Patients & PFS & OS \\
\hline \multirow[t]{2}{*}{ TARGET trial [12] } & \multirow{2}{*}{$\begin{array}{l}\text { Sorafenib } 400 \mathrm{mg} \text { PO } \\
\text { twice daily Vs Placebo }\end{array}$} & 451 & 5.5 months & 17.8 months \\
\hline & & 452 & $\begin{array}{l}2.8 \text { months }(\mathrm{HR}=0.44) \\
\quad P<0.01\end{array}$ & $\begin{array}{l}15.2 \text { months } \mathrm{HR}=0.88 \\
\quad P=0.146\end{array}$ \\
\hline \multirow[t]{2}{*}{$\begin{array}{l}\text { Sunitinib Vs Interferon } \\
\text { alfa [13] }\end{array}$} & \multirow[t]{2}{*}{ Sunitinib Vs Interferon } & 375 & $\begin{array}{c}11.0 \text { months Vs } 5.0 \\
\text { months } \mathrm{HR}=0.42\end{array}$ & 26.4 months \\
\hline & & 375 & $P<0.001$ & $\begin{array}{l}21.8 \text { months } \mathrm{HR}=0.821 \\
\quad P=0.051\end{array}$ \\
\hline \multirow{2}{*}{$\begin{array}{l}\text { Pazopanib Vs Placebo } \\
\text { [14] }\end{array}$} & Pazopanib & 290 & 10.2 months & 22.9 months \\
\hline & Placebo & 145 & 5.4 months & $\begin{array}{l}20.5 \text { months } \mathrm{HR}=0.91 \\
\quad P=0.224\end{array}$ \\
\hline \multirow[t]{2}{*}{ COMPARZ [15] } & \multirow[t]{2}{*}{ Sunitinib Vs Pazopanib } & \multirow[t]{2}{*}{$553 / 557$} & 9.5 months & 29.3 months \\
\hline & & & $\begin{array}{l}8.4 \text { months HR }=1.05 \\
95 \% \text { CI } 0.90 \text { to } 1.22\end{array}$ & 28.4 months $\mathrm{HR}=0.91$ \\
\hline \multirow[t]{2}{*}{ CALGB 90206 [20] } & \multirow{2}{*}{$\begin{array}{l}\text { Bevacizumab + Interferon } \\
\text { Vs Interferon }\end{array}$} & 369 & 8.5 months & 18.3months \\
\hline & & 363 & $\begin{array}{l}5.2 \text { months } \mathrm{HR}=0.71 \\
P<0.0001\end{array}$ & $\begin{array}{l}\text { 17.4months } \mathrm{HR}=0.86 \\
P=0.097\end{array}$ \\
\hline \multirow[t]{2}{*}{ AVOREN [19] } & \multirow{2}{*}{$\begin{array}{l}\text { Bevacizumab + Interferon } \\
\text { Interferon }\end{array}$} & 327 & 10.5 months & 23.3 months \\
\hline & & 322 & $\begin{array}{l}5.2 \text { months } \mathrm{HR}=0.63 \\
P=0.0001\end{array}$ & $\begin{array}{l}21.3 \text { months } \mathrm{HR}=0.91 \\
\quad P=0.3360\end{array}$ \\
\hline \multirow[t]{2}{*}{ CABOSUN [21] } & \multirow{2}{*}{$\begin{array}{l}\text { Cabozantinib } 60 \mathrm{mg} \text { daily } \\
\text { Vs Sunitinib } 50 \mathrm{mg} \\
\text { daily } 4 \text { weeks on } 2 \\
\text { weeks off }\end{array}$} & \multirow[t]{2}{*}{157 patients } & 8.6 months & 26.6 months \\
\hline & & & $\begin{array}{l}5.3 \text { months } \mathrm{HR}=0.48 \\
P=0.0008\end{array}$ & $\begin{array}{l}21.2 \text { months } \mathrm{HR}=0.8 \\
\quad P=0.29\end{array}$ \\
\hline \multirow[t]{2}{*}{ AXIS [16] } & \multirow{2}{*}{$\begin{array}{l}\text { Axitinib } 5 \mathrm{mg} \text { twice daily } \\
\text { Vs Sorafenib } 400 \mathrm{mg} \\
\text { twice daily }\end{array}$} & 361 & 6.7 months & 20.1 months \\
\hline & & 362 & $\begin{array}{l}4.7 \text { months } \mathrm{HR}=0.665 \\
\qquad P=0.0001\end{array}$ & $\begin{array}{l}19.2 \text { months } \mathrm{HR}=0.969 \\
\quad P=0.3744\end{array}$ \\
\hline \multirow[t]{2}{*}{ METEOR [17] } & \multirow{2}{*}{$\begin{array}{l}\text { Cabozantinib } 60 \mathrm{mg} \text { daily } \\
\text { Vs Everolimus } 10 \mathrm{mg} \\
\text { daily }\end{array}$} & \multirow[t]{2}{*}{658 patients } & 7.4 months & 21.4 months \\
\hline & & & $\begin{array}{l}3.8 \text { months } \mathrm{HR}=0.58 \\
P<0.0001\end{array}$ & $\begin{array}{l}16.5 \text { months } \mathrm{HR}=0.66 \\
P=0.00026\end{array}$ \\
\hline
\end{tabular}

investigator assessed ORR ( $46 \%$ vs. $18 \%$ ) and a $34 \%$ reduction in rate of progression or death (adjusted hazard ratio $(\mathrm{HR})=0.66,95 \% \mathrm{CI}$ : 0.46 to 0.95 ; onesided $p=0.012)$ in the cabozantinib arm with a similar incidence of grade 3 or 4 AEs (67\% vs. 68\%). Preliminary data on OS, a secondary endpoint, revealed a $20 \%$ decrease in the rate of death with cabozantinib, with median OS of 26.2 versus 21.6 months, although the difference was not statistically significant $(p=0.29)$.

In 2012, the AXIS study published results from a study of 723 patients comparing axitinib to sorafenib in patients with $\mathrm{mRCC}$ who had progressed on previous systemic therapy (35\% of whom were treated with cytokines, and the rest had prior treatment with sunitinib, bevacizumab plus interferon, or temsirolimus) [16]. Initial results showed the axitinib arm had improved PFS of 2 months compared to sorafenib (median PFS, 6.7 vs. 4.7 , one-sided $p<0.0001$ ) which improved in the updated results (Median PFS, 8.3 vs. 5.7 months, one-sided $p<0.0001$ ). Improvement in PFS was greater in those previously treated with cytokines (12.2 vs. 8.2 months). ORR was also improved in the axitinib arm ( $23 \%$ vs. $12 \%)$, but OS was similar in both arms. Adverse events were also similar in both arms.

Another landmark study, the METEOR trial, investigated cabozantinib vs. everolimus in 658 patients who had progressed after anti-angiogenic therapy directed against VEGF [17]. Sixty-nine percent of patients had only received 1 prior treatment while the remaining had received at least 2 prior therapies. Cabozantinib resulted in improved in PFS (7.4 vs. 3.8 months, $p<0.001)$, ORR $(17 \%$ vs. $3 \%, p<0.001)$ and OS (21.4 vs. 16.5 months, HR $=0.66, p=0.00026)$. Remarkably, treatment with cabozantinib resulted in the longest PFS in a phase III trial, in the salvage therapy setting. Over $99 \%$ of patients in both arms reported an $\mathrm{AE}$ of any grade, but there was a greater incidence of grade 3-4 AEs in the cabozantinib arm (68\% vs. 58\%). More frequent grade 3-4 AEs with cabozantinib included hand-foot syndrome, hypertension, diarrhea, nausea and thromboembolic events [17]. Also reported in 2015, a phase 2 study investigated lenvatinib, a tyrosine kinase inhibitor of VEGF receptors 1-3, fibroblast growth factor (FGF) 
receptors 1-4, platelet-derived growth factor receptor $\alpha$ (PDGFR $\alpha)$, RET and KIT, in 153 patients with $\mathrm{mRCC}$ who had progressed after VEGF-targeted therapy [18]. Patients were randomized into 3 arms: combination lenvatinib and everolimus vs. lenvatinib monotherapy vs. everolimus monotherapy. Respectively, PFS (14.6 vs. 7.4 vs. 5.5 months) and OS (25.5 vs 18.4 vs 15.4 months) were greater in the combination arm but only met statistical significance for the primary endpoint which was PFS of lenvatinib and everolimus compared to everolimus monotherapy. Combination therapy was more toxic than everolimus monotherapy (grade 3-4 AEs 71\% vs. 50\%) with significantly greater diarrhea in the combination arm. These studies led to FDA approvals for cabozantinib, and lenvatinib plus everolimus, in advanced RCC patients who had previously failed an anti-angiogenic agent.

\section{mTOR INHIBITORS}

Mutations in phosphatidylinositol-3 kinase (PI3K), a kinase upstream of mTOR, were both common in $\mathrm{mRCC}$ and amenable to targeted therapy [23]. In 2007, an mTOR inhibitor temsirolimus achieved FDA approval for previously untreated mRCC patients in poor prognosis category based on a study showing improvement in OS compared to interferon (10.9 vs. 7.3 months, $p=0.008)$ in the Global ARCC trial [24]. Notably, although not the primary endpoint, there was only a modest improvement in PFS over interferon by independent radiographic assessment (5.5 vs. 3.1 months). Combination interferon with temsirolimus was also evaluated but did not improve PFS or OS.

This was followed by the RECORD-1 trial [25] investigating everolimus vs. placebo in those who progressed after treatment with sunitinib or sorafenib. The everolimus arm showed improved PFS (4.9 vs. 1.9 months, $p<0.001$ ) but was also associated with increased rates of stomatitis, rash and fatigue. Similar to temsirolimus studies, there was a $3 \%$ incidence of severe non infectious pneumonitis noted.

\section{NEGATIVE TRIALS IN METASTATIC RCC}

The SELECT trial attempted to evaluate the role of a biomarker carbonic anhydrase IX in predicting response to high dose IL-2. Unfortunately this study showed that this biomarker was ineffective as a predictive factor for guiding IL-2 therapy. A study of a FGFR inhibitor called dovtinib in comparison with sorafenib was conducted and results revealed no benefit in the third line setting after failure of one anti-VEGF and MTOR inhibitor therapy [26]. Another study investigated axitinib vs. sorafenib in 288 previously untreated patients. Although there was an improvement in ORR ( 32 vs. 15 months) and a non-significant trend towards improved PFS (10.0 vs. 6.5 months) in the axitinib arm, the OS favored sorafenib [27]. The TIVO - 1 trial evaluated front line tivozanib and compared it with sorafenib. The PFS was improved, however OS was no different and in fact appeared to favor the sorafenib arm $(\mathrm{HR}=1.245$, $p=0.1$ ) [28]. Multiple trials of combination regimens of anti-VEGF and MTOR inhibitors compared to single agent therapy, consistently showed no benefit and increased toxicities.

Trials attempting to define the optimal sequence of therapy were also conducted. Everolimus, an mTOR inhibitor, was compared to sunitinib in 471 previously untreated patients in the RECORD-3 [29] study using a crossover treatment design following disease progression. Primary endpoint was non-inferiority of PFS achieved with everolimus as initial therapy as compared to sunitinib in the first-line therapy setting. In addition to inferior PFS in the everolimus arm (7.9 vs. 10.7 months), the combined PFS was inferior with "everolimus followed by sunitinib" as compared to "sunitinib followed by everolimus" (Median PFS, 21.1 vs. 25.8 months). The median OS also favored "sunitinib followed by everolimus" rather than the reverse (32 vs. 22.4 months) [29]. A 2015 phase II randomized trial evaluated bevacizumab in a 4arm first-line study: bevacizumab monotherapy vs. bevacizumab and temsirolimus vs. bevacizumab and sorafenib vs. sorafenib and temsirolimus [30]. There was no significant improvement in PFS, the primary endpoint, but toxicity was significantly greater in the combination arms. Forty-four percent of patients in the bevacizumab monotherapy arm had grade 3-5 AEs compared to 77 to $84 \%$ of those in the combination arms.

Vaccine testing in advanced RCC has yielded disappointing results. For instance a phase III trial of 733 patients randomized to receive either a modified vaccinia encoding tumor antigen 5T4 versus placebo in addition to standard therapy, revealed no difference in OS (Median 20.1 months with vaccine and 12.4 months with placebo, $p=0.55$ ) [31]. Similarly, after encouraging phase 2 results, a phase 3 trial studied IMA901, a vaccine of 10 tumor-associated peptides, in combination with sunitinib in previously untreated 
mRCC [32]. Although the peptide vaccine was well tolerated, there were no improvements noted in clinical outcomes compared to sunitinib monotherapy.

\section{IMMUNE CHECKPOINT INHIBITOR BASED THERAPIES [TABLE 3]}

Nivolumab, a monoclonal antibody directed against programmed death-1 receptor (PD-1), is an immune checkpoint inhibitor that results in reversing tumor induced immune suppression and stimulating antitumor immunity. Initially developed for metastatic melanoma and non-small cell lung cancer, a landmark Checkmate 025 study compared nivolumab to everolimus in the second-line setting after progression on sorafenib or sunitinib [33]. Although PFS was similar in both arms (4.6 vs. 4.4 months), the primary endpoint of OS was superior in the nivolumab arm (Median OS 25.0 vs. 19.6 months, HR for death $=0.73, p=0.002$ ). ORR was also greater in the nivolumab arm (25\% vs. $5 \%)$ and there were significantly fewer grade 3-4 AEs in the nivolumab arm (19\% vs. $37 \%)$.

The recently reported results of the combination of nivolumab ( $3 \mathrm{mg} / \mathrm{kg}$ dose)with ipilimumab $(1 \mathrm{mg} / \mathrm{kg}$ dose) every 3 weeks for a maximum of 4 doses followed by maintenance therapy with nivolumab every 2 weeks, as compared to sunitinib will likely lead to a true paradigm shift in the therapy of untreated metastatic RCC [34]. Checkmate 214 was a trial that was conducted in all patients with untreated $\mathrm{mRCC}$ and was designed with specific ORR, PFS and OS endpoints in overall intent to treat population and specifically co-primary endpoints the intermediate and poor risk RCC. Stratification was conducted by favorable vs intermediate vs poor risk (IMDC prognostic scores of 0, 1-2 and 3-6 respectively) and by country; US vs Europe and rest of World. The primary endpoint was ORR, PFS and OS in the intermediate/poor risk subgroup. Secondary endpoints were ORR, PFS and OS in the ITT patient population. Overall alpha error of 0.05 was split between the co-primary endpoints with 0.001 assigned to ORR, 0.009 assigned to PFS and 0.04 allocated to OS. The study design had $80 \%$ power for the PFS analysis and $90 \%$ power for OS analysis. In the intermediate and poor risk group, the ORR was $42 \%$ (9\%CR) in the $\mathrm{N}+\mathrm{I}$ group and $27 \%(1 \% \mathrm{CR})$ in the sunitinib group ( $p=0.0001)$. The median duration of response was 16 months in the sunitinib arm with $63 \%$ continuing in response, and has not yet been reached in the $\mathrm{N}+\mathrm{I}$ arm with $72 \%$ of the patients continuing in response. The median PFS was 8.4 months and 11.6 months $(p=0.0331)$ in the sunitinib and $\mathrm{N}+\mathrm{I}$ arms respectively, however the difference was not statistically significant. The OS was significantly improved in the $\mathrm{N}+\mathrm{I}$ group with median OS not yet reached and the median OS was 26 months in sunitinib group $(p<0.0001)$. The overall patient population showed a statistically significant difference in OS only (median 36 months with sunitinib and not reached with $\mathrm{N}+\mathrm{I}$, $p=0.0003$ ) but no significant differences in ORR (39\% and 32\% for $\mathrm{N}+\mathrm{I}$ and sunitinib, $p=0.0191$ ) and PFS (Medians 12.4 and 12.3 months in $\mathrm{N}+\mathrm{I}$ and sunitinib groups, $p=0.8498$ ). Conversely, the 249 patient favorable risk group showed a higher response rate and longer PFS favoring the sunitinib arm (52\% vs $29 \%, p=0.0002$ and median PFS of 25.1 months vs 15.3 months, $p=0.0001)$. The intermediate and poor risk patient population (79\%/21\% distribution) revealed a significant improvement in ORR and OS favoring $\mathrm{N}+\mathrm{I}$.

The PDL-1 expression was checked in the patients with available tissue and correlated with clinical endpoints. The subgroup with PDL-1 expression of $1 \%$ or greater appeared to demonstrate ORR of $58 \%$ with $\mathrm{N}+\mathrm{I}$ therapy as compared to ORR ranging from $22-35 \%$ with either therapy in the PDL- $1<1 \%$ subgroup. The PDL- $1 \geq 1 \%$ group had a median PFS of 5.9 months on sunitinib therapy as compared to a median of 22.9 months with $\mathrm{N}+\mathrm{I}(p=0.0003)$. On the other hand, the PDL- $1<1 \%$ subgroup of patients showed no significant difference in PFS (median 10.4 months and 11 months in $\mathrm{N}+\mathrm{I}$ and sunitinib arms, $p=0.9670$ ). In summary the trial demonstrated an OS outcome favoring $\mathrm{N}+\mathrm{I}$ therapy, however the PDL-1 < $1 \%$ patients had better or similar outcomes with sunitinib and the PDL- $1 \geq 1 \%$ subgroup had improved outcomes with N+I. Similarly within the intermediate and poor risk subgroups the PDL- $1 \geq 1 \%$ patients, the clinical outcomes favored $\mathrm{N}+\mathrm{I}$ therapy and in the PDL- $1<1 \%$ subgroup no clear benefit was noted with $\mathrm{N}+\mathrm{I}$ therapy. The PDL-1 subgroup results are not adequately powered to be conclusive but should be viewed as hypothesis generating. The study results also have to be tempered with the knowledge that on the control arm of sunitinib, only $20 \%$ of the patients have received single agent nivolumab therapy. So a real world comparison with the existing standard of care therapy (anti-VEGF therapy followed by nivolumab) in the US cannot be made. This study will shift the paradigm of front line therapy from an antiVEGF core to an immune therapy based regimen. 
Table 3

Immune checkpoint inhibition based landmark trials

\begin{tabular}{|c|c|c|c|c|}
\hline Study [Ref] & Agent & Patients & PFS & OS \\
\hline \multirow[t]{6}{*}{ Checkmate 025 [33] } & $\begin{array}{l}\text { Nivolumab } 3 \mathrm{mg} / \mathrm{kg} \\
\text { Vs }\end{array}$ & 406 & 4.6 months & 25.0 months \\
\hline & Everolimus $10 \mathrm{mg}$ & PDL- $1>1 \%$ & & 21.8 months \\
\hline & daily & PDL- $1<1 \%$ & & 27.4 months \\
\hline & & 397 & $\begin{array}{l}4.5 \text { months } \mathrm{HR}=0.88 \\
\quad P=0.11\end{array}$ & $\begin{array}{l}19.6 \text { months } \\
\mathrm{HR}=0.73 P=0.002\end{array}$ \\
\hline & & PDL- $1 \geq 1 \%$ & & 18.8 months \\
\hline & & PDL- $1<1 \%$ & & 21.2 months \\
\hline \multirow[t]{8}{*}{ Checkmate 214 [34] } & Nivolumab 3 mg/kg + & ITT & 12.4 months & Not reached \\
\hline & $\begin{array}{l}\text { Ipilimumab } 1 \mathrm{mg} / \mathrm{kg} \\
\text { for } 4 \text { doses } \mathrm{Vs} \\
\text { Sunitnib } 50 \mathrm{mg} \text { daily }\end{array}$ & 1096 & $\begin{array}{c}12.5 \text { months } \\
\mathrm{HR}=0.98 \\
P=0.8498\end{array}$ & $\begin{array}{l}32.9 \text { months } \\
\mathrm{HR}=0.68 \\
P=0.0003\end{array}$ \\
\hline & 4 weeks on 2 weeks & Favorable risk & 15.3 months & \\
\hline & off & 249 & $\begin{array}{l}25.3 \text { months } \\
\mathrm{HR}=2.19 \\
P=0.0001\end{array}$ & \\
\hline & & $\begin{array}{l}\text { Intermediate/Poor } \\
847\end{array}$ & 11.6 months & Not reached \\
\hline & & & $\begin{array}{l}8.4 \text { months } \mathrm{HR}=0.82 \\
\quad P=0.0331\end{array}$ & $\begin{array}{c}26.0 \text { months } \\
\mathrm{HR}=0.63 \\
P<0.0001\end{array}$ \\
\hline & & PDL-1 +ve: $\geq 1 \%: 214$ & $\begin{array}{l}22.8 \text { months } 5.9 \\
\text { months } \mathrm{HR}=0.48 \\
P=0.0003\end{array}$ & Not reported \\
\hline & & PDL-1 -ve<1\%: 582 & $\begin{array}{l}11 \text { months } 10.4 \\
\text { months } \mathrm{HR}=1.0 \\
P=0.9670\end{array}$ & \\
\hline \multirow[t]{9}{*}{ IMmotion 151 [35] } & Atezolizumab $1200 \mathrm{mg}$ & Total 363 & & \\
\hline & $\begin{array}{l}\text { IV every } 21 \text { days }+ \\
\text { Bevacizumab }\end{array}$ & $\begin{array}{l}\text { PDL-1 +ve } \geq 1 \% \\
\text { (Investigator assessed }\end{array}$ & 11.2 months & Not reached \\
\hline & $\begin{array}{l}15, \mathrm{~g} / \mathrm{kg} \text { IV every } 21 \\
\text { days Vs Sunitinib }\end{array}$ & $\begin{array}{l}\text { PFS as prespecified } \\
\text { Primary endpoint) }\end{array}$ & $\mathrm{HR}=0.74 P=0.02$ & \\
\hline & $\begin{array}{l}50 \mathrm{mg} \text { daily orally } 4 \\
\text { weeks on } 2 \text { weeks off }\end{array}$ & 178 & 7.7 months & 25.3 months \\
\hline & & 184 & & \\
\hline & $\begin{array}{l}\text { ITT Atezolizumab + } \\
\text { Bevacizumab Vs } \\
\text { Sunitinib }\end{array}$ & & $\begin{array}{c}11.2 \text { months } \\
\mathrm{HR}=0.83\end{array}$ & $\begin{array}{l}\text { Not reached } \\
\text { HR }=0.81 P=0.09 \\
\text { (immature results, } \\
29 \% \text { events) }\end{array}$ \\
\hline & & $\begin{array}{l}\text { OS as co-primary } \\
\text { endpoint }\end{array}$ & 8.4 months & Not reached \\
\hline & & 454 & & \\
\hline & & 460 & & \\
\hline
\end{tabular}

\section{ONGOING OR RECENT CLINICAL TRIALS FOR UNTREATED mRCC}

While the landscape of kidney cancer therapy is rapidly evolving, there are many clinical trials at various stages investigating first-line therapy for mRCC (Table 4).

Numerous immunotherapy agents are under active investigation in the first-line setting for mRCC, including 7 trials investigating immune checkpoint inhibitors. IMmotion 151 (NCT02420821) recently reported results of this phase III randomized trial of atezolizumab (1200 mg IV every 3 weeks) and bevacizumab ( $15 \mathrm{mg} / \mathrm{kg}$ every 3 weeks) compared to standard therapy of sunitinib (50 mg daily, 4 weeks on 2 weeks off). Investigator assessed PFS in the PDL$1+$ ve subgroup was the co-primary endpoint of the study (prespecified significance level at 0.04), along with OS (prespecified alpha at 0.01 ) in the intent to treat (ITT) population [35]. Improved efficacy with the atezolizumab and bevacizumab combination was noted in the PDL-1 positive group $(\geq 1 \%)$. 
Table 4

Interventional trials investigating first-line therapy of novel agents in $\mathrm{mRCC}$

\begin{tabular}{|c|c|c|c|c|c|}
\hline ID & Phase & Arms & Primary Outcome & Patients & Completion \\
\hline NCT02420821 & 3 & Atezolizumab + bevacizumab vs. sunitinib & PFS, OS* & 900 & $7 / 2020$ \\
\hline NCT02853331 & 3 & Pembrolizumab + axitinib vs. sunitinib & PFS, OS & 840 & $12 / 2019$ \\
\hline NCT02811861 & 3 & $\begin{array}{l}\text { Lenvatinib }+ \text { everolimus vs. lenvatinib }+ \text { pembrolizumab } \\
\text { vs. sunitinib }\end{array}$ & PFS & 735 & $1 / 2020$ \\
\hline NCT02684006 & 3 & Avelumab + axitinib vs. sunitinib & PFS & 583 & $6 / 2018$ \\
\hline NCT01582672 & 3 & AGS-003 + sunitinib+/-AGS003/placebo & OS & 450 & $4 / 2017$ \\
\hline NCT02996110 & 2 & Nivolumab + ipilimumab vs. nivolumab + BMS-986016 & ORR, DOR, PFSR & 650 & $1 / 2022$ \\
\hline NCT03141177 & 2 & Nivolumab vs. sunitinib or pazopanib after 3 months TKI & OS & 244 & $11 / 2022$ \\
\hline NCT01391130 & 3 & Cabozantinib+Ipi+ Nivo vs cabozabtinib + nivo vs sunitinib & PFS & 1014 & $8 / 2022$ \\
\hline
\end{tabular}

*OS and investigator PFS only calculated for those with detectable PD-L1 tumor expression. ${ }^{* *}$ Non-clear cell $\mathrm{mRCC} . \mathrm{mRCC}=$ advanced or metastatic renal cell carcinoma, $\mathrm{PFS}=$ progression free survival, $\mathrm{OS}=$ overall survival, $\mathrm{ORR}=$ objective response rate, $\mathrm{DOR}=\mathrm{duration}$ of response, $\mathrm{PFSR}=$ progression free survival rate, irAEs $=$ immune-related adverse events, $\mathrm{TKI}=$ tyrosine kinase inhibitor.

Median PFS was 11.2 months in the combination arm as compared to 7.7 months in the sunitinib arm ( $p=0.02, \mathrm{HR}=0.74)$. However, the independent radiology review PFS results showed lack of statistically significant difference between the two arms (median 8.9 months vs 7.2 months, HR $=0.93,95 \%$ confidence interval $0.72-1.21$ ). Preliminary but immature OS results in ITT population favor the combination arm over sunitinib with HR of $0.81(p=0.09)$.

Future trials with control arm of sunitinib may have to be modified if $\mathrm{N}+\mathrm{I}$ becomes the FDA approved front line therapy. Nivolumab is also being studied in two phase 2 trials of combination immunotherapy; NCT02996110 and NCT02959554. The aforementioned trial plans to enroll 650 patients and are comparing $\mathrm{N}+\mathrm{I}$ with nivolumab and BMS-986016, a monoclonal antibody checkpoint inhibitor directed against lymphocyte activation gene-3 (LAG-3). The other study is enrolling 244 patients and comparing nivolumab to sunitinib or pazopanib after treating patients for 10-12 weeks with a tyrosine kinase inhibitor. Pembrolizumab, another PD-1 monoclonal antibody, is currently being studied in combination with axitinib compared to sunitinib in a phase 3 trial of 840 patients with expected completion in 2019 (NCT02853331). Another phase 3 trial of 735 patients, NCT02811861, is comparing the combination of pembrolizumab and lenvatinib against combination lenvatinib and everolimus as well as sunitinib monotherapy. Checkpoint inhibitors targeting PD-1 ligand (PD-L1), avelumab and atezolizumab, are also enrolling patients for first-line studies. In a phase 3 trial of 583 patients, avelumab is being studied in combination with axitinib versus the comparator sunitinib (NCT02684006). Pembrolizumab and epacadostat and Cabozantinib with $\mathrm{N}+\mathrm{I}$ combinations are entering phase III testing.
AGS-003 is a personalized immunotherapy of mature autologous dendritic cells which are coelectroporated with the both synthetic and the patient's tumor RNA. Designed to achieve the immunomodulatory effects of HDIL-2 with a more favorable toxicity profile, AGS-003 was studied in combination with sunitinib in a phase II study of 22 patients with low or intermediate risk mRCC. There were no CRs, but 9 patients had a partial response and the median PFS and OS were encouraging (11.2 and 30.2 months, respectively) [36]. The phase 3 trial, ADAPT (NCT01582672), is completed but results have not yet been reported. LY2510924 $[\mathrm{X} 4 \mathrm{P}]$ is a novel cyclic peptide which inhibits CXCR4 , a chemokine receptor which has been shown to be important in tumorgenesis [37]. Hif-1 inhibitors such as PT3285 and PT3299 are now under clinical evaluation.

\section{ROLE OF SURGERY IN METASTATIC SETTING}

One of the earlier landmark advance in therapy of RCC was made with two randomized trials $[38,39]$ that compared $\mathrm{CN}$ followed by interferon therapy as compared to interferon therapy alone. The SWOG study demonstrated a significant improvement in the OS of the CN group. Similar results were also noted in an EORTC trial. Hence $\mathrm{CN}$ became a routine consideration in the initial management of metastatic RCC. However whether this benefit of $\mathrm{CN}$ is also noted in the era of targeted therapy is largely unknown [40]. The CARMENA trial (NCT0093003) results are likely to be reported shortly and the study is a comparison of the control arm of $\mathrm{CN}$ followed by sunitinib to sunitinib alone. A recently reported randomized study (SURTIME/NCT01099423) addressed the 
question of benefit of $\mathrm{CN}$ in conjunction with sunitinib [41]. Although the study had slow accrual and had to be stopped at a decreased sample size (total 99 patients), the results are intriguing. The results revealed that patients treated with $\mathrm{mRCC}$ have improved OS outcomes with sunitinib followed by deferred $\mathrm{CN}$ as compared to immediate $\mathrm{CN}$ followed by sunitinib therapy. There was no difference in progression free rates in the two arms. In the era of immune therapy there is also a data that indicates the enhancement of efficacy, with the primary tumor not being resected by increasing the tumor mutation burden and causing antigen spread. [42-44]. While prospective results are pending, it is paramount that the treatment decision for $\mathrm{CN}$ be based on an individual patient's performance and prognostic status and made in conjunction with multidisciplinary input. Though no specific guidelines yet exist, a reasonable approach may be to exclude those who did not benefit from $\mathrm{CN}$ in the IMDC study [45]. These included those with at least 4 poor IMDC prognostic factors: time from diagnosis to treatment less than 1 year, KPS less than 80, anemia, neutrophilia and thrombocytosis. Additionally, those with anticipated OS shorter than 1 year may not benefit from $\mathrm{CN}$ [39].

\section{BIOMARKER LANDMARK TRIALS}

Biomarker selection to help guide therapy would be a helpful tool, however no predictive markers have been validated to date. The prognostic biomarkers are mainly based on clinical criteria. The landmark reports of the Memorial Sloan Kettering [46] and the Heng criteria [22] are widely adopted and routinely used for risk stratification in clinical management and in clinical trials. The International Metastatic RCC Database Consortium, reported by Heng et al. established and validated the risk factors of anemia, thrombocytosis, neutrophilia, hypercalcaemia, Karnofsky performance status $<80 \%$, and $<1$ year from diagnosis to treatment as independent predictors of poor OS. Median OS was 43.2 months (95\% CI 31.4-50.1) in the favorable risk group (no risk factors; 157 patients), 22.5 months (18.7-25.1) in the intermediate risk group (one to two risk factors; 440 patients), and 7.8 months $(6.5-9.7)$ in the poor risk group (three or more risk factors; 252 patients). PDL1 expression, a useful marker in other malignancies failed to predict efficacy of immune therapy with single agent nivolumab in advanced RCC, but maybe a powerful predictive marker in the Checkmate 214 trial. The neutrophil lymphocyte ratio and duration of prior anti-VEGF therapy are emerging as promising biomarkers to predict response to immune therapy within RCC [47, 48]. The recent reports of BAP1, SETD2 and PBRM-1 may possibly impact risk predictions in the future [49]. Novel targets involving resistance pathways such as CMET, CXCR-4 [X4P] and HIF-1 Alfa [PT2385] are under clinical investigation [50]. Immune modulators such as ido-1 inhibitors, ox-40 and lag-3 inhibitors are also novel agents of interest and may need associated predictive biomarkers to advance in the therapeutic arena.

\section{CONCLUSION}

The field of kidney cancer has made rapid strides in therapeutic development and a lion's share of the credit goes to well designed and rigorously conducted clinical trials and the patients that participated in it. New advances have improved the rate of response, survival and treatment-related toxicities for patients with $\mathrm{mRCC}$. While new discoveries in targeted therapies are paralleled by those in immunotherapy, the treatment paradigm continues to evolve. Despite the FDA approvals of multiple agents, clinical trials continue to be the mainstay of making advances in treatment of RCC and every step forward is attributed to patient participation in therapeutic studies.

\section{REFERENCES}

[1] Clark JI, Atkins MB, Urba WJ, Creech S, Figlin RA, Dutcher JP, et al. Adjuvant high-dose bolus interleukin2 for patients with high-risk renal cell carcinoma: A cytokine working group randomized trial. J Clin Oncol. 2003;21:3133-40.

[2] Messing EM, Manola J, Wilding G. Propert K, Fleischmann J, Crawford ED, et al. Phase III study of interferon alfa-NL as adjuvant treatment for resectable renal cell carcinoma: An Eastern Cooperative Oncology Group/Intergroup trial. J Clin Oncol. 2003;21:1214-22.

[3] Haas NB, Manola J, Uzzo RG, Flaherty KT, Wood CG, Kane $\mathrm{C}$, et al. Adjuvant sunitinib or sorafenib for high-risk, nonmetastatic renal-cell carcinoma (ECOG-ACRIN E2805): A double-blind, placebo-controlled, randomised, phase 3 trial. Lancet. 2016;387:2008-16.

[4] Ravaud A, Motzer RJ, Pandha HS, George DJ, Pantuck AJ, Patel A, et al. Adjuvant sunitinib in high-risk renal-cell carcinoma after nephrectomy. N Engl J Med. 2016;375:2246-54.

[5] Motzer RJ, Haas NB, Donskov F, Gross-Goupil M, Varlamov S, Kopyltsov E, et al. Randomized phase III trial of adjuvant pazopanib versus placebo after nephrectomy in patients with localized or locally advanced renal cell carcinoma. J Clin Oncol. 2017;73:5324. [Epub] 
[6] Harshman LC, Xie W, Moreira RB, Bossé D, Ruiz Ares GJ, Sweeney CJ, Choueiri TK. Evaluation of disease-free survival as an intermediate metric of overall survival in patients with localized renal cell carcinoma: A trial-level meta-analysis. Cancer. 2017;10:1002.

[7] Fyfe G, Fisher RI, Rosenberg SA, Sznol M, Parkinson DR, Louie AC. Results of treatment of 255 patients with metastatic renal cell carcinoma who received highdose recombinant interleukin-2 therapy. Journal of Clinical Oncology. 1995; 13:688-96.

[8] Fisher RI, Rosenberg SA, Fyfe G. Long-term survival update for high-dose recombinant interleukin-2 in patients with renal cell carcinoma. Cancer J Sci Am. 2000;6:S55-7.

[9] Yang JC, Sherry RM, Steinberg SM, Topalian SL, Schwartzentruber DJ, Hwu P, et al. Randomized study of high-dose and low-dose interleukin-2 in patients with metastatic renal cancer. Journal of Clinical Oncology. 2003;21:3127-32

[10] McDermott DF, Cheng SC, Signoretti S, Margolin KA, Clark JI, Sosman JA, et al. The high-dose aldesleukin "select" trial: A trial to prospectively validate predictive models of response to treatment in patients with metastatic renal cell carcinoma. Clin Cancer Res. 2015;21:561-8.

[11] Clark JI, Wong MK, Kaufman HL, Daniels GA, Morse MA, McDermott DF, et al. Impact of sequencing targeted therapies with high-dose interleukin-2 immunotherapy: An analysis of outcome and survival of patients with metastatic renal cell carcinoma from an on-going observational IL2 clinical trial: PROCLAIM. Clin Genitourin Cancer. 2017;15:31-41.

[12] Escudier B, Eisen T, Stadler WM, Szczylik C, Oudard S, Siebels M, et al. Sorafenib in advanced clear-cell renal-cell carcinoma. N Engl J Med. 2007;356:125-34.

[13] Motzer RJ, Rini BI, Bukowski RM, Curti BD, George DJ, Hudes GR, et al. Sunitinib in patients with metastatic renal cell carcinoma. JAMA. 2006;295:2516-24.

[14] Sternberg CN, Davis ID, Mardiak J, Szczylik C, Lee E, Wagstaff J, et al. Pazopanib in locally advanced or metastatic renal cell carcinoma: Results of a randomized phase III trial. J Clin Oncol. 2010;28:1061-8.

[15] Motzer RJ, Hutson TE, Cella D, Reeves J, Hawkins R, Guo $\mathrm{J}$, et al. Pazopanib versus sunitinib in metastatic renal-cell carcinoma. N Engl J Med. 2013;369:722-31.

[16] Motzer RJ, Escudier B, Tomczak P, Hutson TE, Michaelson $\mathrm{MD}$, Negrier S, et al. Axitinib versus sorafenib as secondline treatment for advanced renal cell carcinoma: Overall survival analysis and updated results from a randomised phase 3 trial. Lancet Oncol. 2013;14:552-62.

[17] Choueiri TK, Escudier B, Powles T, Mainwaring PN, Rini BI, Donskov F, et al. Cabozantinib versus everolimus in advanced renal-cell carcinoma. $\mathrm{N}$ Engl $\mathrm{J}$ Med. 2015;373:1814-23.

[18] Motzer RJ, Hutson TE, Glen H, Michaelson MD, Molina A, Eisen T, et al. Lenvatinib, everolimus, and the combination in patients with metastatic renal cell carcinoma: A randomised, phase 2, open-label, multicentre trial. Lancet Oncol. 2015;16:1473-82.

[19] Escudier B, Pluzanska A, Koralewski P, Ravaud A, Bracarda $\mathrm{S}$, Szczylik C, et al. Bevacizumab plus interferon alfa-2a for treatment of metastatic renal cell carcinoma: A randomised, double-blind phase III trial. The Lancet. 2007;370:2103-11.

[20] Rini BI, Halabi S, Rosenberg JE, Stadler WM, Vaena DA, Archer L, Atkins JN, Picus J, Czaykowski P, Dutcher J, Small EJ. Phase III trial of bevacizumab plus interferon alfa versus interferon alfa monotherapy in patients with metastatic renal cell carcinoma: final results of CALGB 90206. J Clin Oncol. 2010 May 1;28(13):2137-43.

[21] Choueiri TK, Halabi S, Sanford BL, Hahn O, Michaelson MD, Walsh MK, et al. Cabozantinib versus sunitinib as initial targeted therapy for patients with metastatic renal cell carcinoma of poor or intermediate risk: The Alliance A031203 CABOSUN trial. J Clin Oncol. 2017;35: 591-7.

[22] Heng DY, Xie W, Regan MM, Harshman LC, Bjarnason GA, Vaishampayan UN, et al. External validation and comparison with other models of the International Metastatic Renal-Cell Carcinoma Database Consortium prognostic model: A population-based study. Lancet Oncol. 2013;2:141-8

[23] Hennessy BT, Smith DL, Ram PT, Lu Y, Mills GB. Exploiting the PI3K/AKT pathway for cancer drug discovery. Nat Rev Drug Discov. 2005;4:988-1004.

[24] Hudes G, Carducci M, Tomczak P, Dutcher J, Figlin R, Kapoor A, et al. Temsirolimus, interferon alfa, or both for advanced renal-cell carcinoma. New England Journal of Medicine. 2007;356:2271-81.

[25] Motzer RJ, Escudier B, Oudard S, Hutson TE, Porta C, Bracarda $\mathrm{S}$, et al. Efficacy of everolimus in advanced renal cell carcinoma: A double-blind, randomised, placebo-controlled phase III trial. Lancet. 2008;372:449-56.

[26] Motzer RJ, Porta C, Vogelzang NJ, Sternberg CN, Szczylik $\mathrm{C}$, Zolnierek J, et al. Dovitinib versus sorafenib for third-line targeted treatment of patients with metastatic renal cell carcinoma: An open-label, randomised phase III trial. Lancet Oncol. 2014;5:286-96.

[27] Hutson TE, Lesovoy V, Al-Shukri S, Stus VP, Lipatov $\mathrm{ON}$, Bair AH, et al. Axitinib versus sorafenib as first-line therapy in patients with metastatic renal-cell carcinoma: A randomised open-label phase 3 trial. Lancet Oncol. 2013;14:1287-94.

[28] Motzer RJ, Nosov D, Eisen T, Bondarenko I, Lesovoy $\mathrm{V}$, Lipatov $\mathrm{O}$, et al. Tivozanib versus sorafenib as initial targeted therapy for patients with metastatic renal cell carcinoma: Results from a phase III trial. J Clin Oncol. 2013;31:3791-9.

[29] Motzer RJ, Barrios CH, Kim TM, Falcon S, Cosgriff T, Harker WG, et al. Phase II randomized trial comparing sequential first-line everolimus and second-line sunitinib versus first-line sunitinib and second-line everolimus in patients with metastatic renal cell carcinoma. J Clin Oncol. 2014;32:2765-72.

[30] Flaherty KT, Manola JB, Pins M, McDermott DF, Atkins MB, Dutcher JJ, et al. BEST: A randomized phase II study of vascular endothelial growth factor, RAF kinase, and mammalian target of rapamycin combination targeted therapy with bevacizumab, sorafenib, and temsirolimus in advanced renal cell carcinoma- a trial of the ECOG-ACRIN cancer research group (E2804). J Clin Oncol. 2015;33:2384-91.

[31] Amato RJ, Hawkins RE, Kaufman HL, Thompson JA, Tomczak P, Szczylik C, McDonald M, Eastty S, Shingler WH, de Belin J, Goonewardena M, Naylor S, Harrop R. Vaccination of metastatic renal cancer patients with MVA-5T4: A randomized, double-blind, placebo-controlled phase III study. Clin Cancer Res. 2010;16(22):5539-47.

[32] Rini B, Stenzl A, Zdrojowy R, Kogan M, Shkolnik M, Oudard S, et al. IMA901, a multipeptide cancer vaccine, plus sunitinib versus sunitinib alone, as first-line therapy for advanced or metastatic renal cell carcinoma (IMPRINT): A multicentre, open-label, randomised, controlled, phase 3 trial. J Clin Oncol. 2016;17:1599-611. 
[33] Motzer RJ, Escudier B, McDermott DF, George S, Hammers HJ, Srinivas $S$, et al. Nivolumab versus everolimus in advanced renal-cell carcinoma. $\mathrm{N}$ Engl $\mathrm{J}$ Med. 2015;373:1803-13.

[34] Escudier B, et al. CheckMate 214: Efficacy and safety of nivolumab + ipilimumab (N+I) v sunitinib (S) for treatmentnaïve advanced or metastatic renal cell carcinoma (mRCC), including IMDC risk and PD-L1 expression subgroups: ESMO 2017 LBA 5 abstract. https://news.bms.com/pressrelease/corporatefinancial-news/checkmate-214-study-eval uating-opdivo-combination-yervoy-stopp

[35] Motzer RJ, Powles T, Atkins MB, et al. IMmotion151: A Randomized Phase III Study of Atezolizumab Plus Bevacizumab vs Sunitinib in Untreated Metastatic Renal Cell Carcinoma (mRCC) ASCO GU symposium 2018.

[36] Amin A, Dudek AZ, Logan TF, Lance RS, Holzbeierlein JM, Knox JJ, et al. Survival with AGS-003, an autologous dendritic cell-based immunotherapy, in combination with sunitinib in unfavorable risk patients with advanced renal cell carcinoma (RCC): Phase 2 study results. J Immunother Cancer. 2015;3:14.

[37] Peng SB, Zhang X, Paul D, Kays LM, Gough W, Stewart J, et al. Identification of LY2510924, a novel cyclic peptide CXCR4 antagonist that exhibits antitumor activities in solid tumor and breast cancer metastatic models. Mol Cancer Ther. 2015;14:480-90.

[38] Flanigan RC, Salmon SE, Blumenstein BA, Bearman SI, Roy V, McGrath PC, et al. Nephrectomy followed by interferon alfa- $2 b$ compared with interferon alfa- $2 b$ alone for metastatic renal-cell cancer. New England Journal of Medicine. 2001;345:1655-9.

[39] Mickisch G, Garin A, Van Poppel H, de Prijck L, Sylvester R. Radical nephrectomy plus interferon-alfabased immunotherapy compared with interferon alfa alone in metastatic renal-cell carcinoma: A randomised trial. Lancet. 2001;358:966-70.

[40] Hanna N, Sun M, Meyer CP, Nguyen PL, Pal SK, Chang $\mathrm{SL}$, et al. Survival analyses of patients with metastatic renal cancer treated with targeted therapy with or without cytoreductive nephrectomy: A National Cancer Data Base study. Journal of Clinical Oncology. 2016;34:3267-75.

[41] Bex A, et al. Immediate versus deferred cytoreductive nephrectomy $(\mathrm{CN})$ in patients with synchronous metastatic renal cell carcinoma (mRCC) receiving sunitinib (EORTC 30073 SURTIME). ESMO 2017 LBA 35.

[42] Gulley JL, Madan RA, Pachynski R, Mulders P, Sheikh NA, Trager J, Drake CG. Role of Antigen Spread and Distinctive Characteristics of Immunotherapy in Cancer Treatment. J Natl Cancer Inst. 2017;109(4).

[43] Hodge JW, Sharp HJ, Gameiro SR. Abscopal regression of antigen disparate tumors by antigen cascade after systemic tumor vaccination in combination with local tumor radiation. Cancer Biother Radiopharm. 2012;27:12-22.

[44] Corbière V, Chapiro J, Stroobant V, Ma W, Lurquin C, Lethé $\mathrm{B}$, et al. Antigen spreading contributes to MAGE vaccination-induced regression of melanoma metastases. Cancer Res. 2011;71:1253-62.

[45] Heng DY, Wells JC, Rini BI, Beuselinck B, Lee JL, Knox JJ, et al. Cytoreductive nephrectomy in patients with synchronous metastases from renal cell carcinoma: Results from the International Metastatic Renal Cell Carcinoma Database Consortium. Eur Urol. 2014;66:704-10.

[46] Motzer RJ, Mazumdar M, Bacik J, Berg W, Amsterdam A, Ferrara J. Survival and prognostic stratification of 670 patients with advanced renal cell carcinoma. J Clin Oncol. 1999;7:2530-40.

[47] Jeyakumar G, Kim S, Bumma N, Landry C, Silski C, Suisham S, et al. Neutrophil lymphocyte ratio and duration of prior anti-angiogenic therapy as biomarkers in metastatic RCC receiving immune checkpoint inhibitor therapy. J Immunother Cancer. 2017;5:82.

[48] Kuzman JA, Stenehjem DD, Merriman J, Agarwal AM, Patel SB, Hahn AW, et al. Neutrophil-lymphocyte ratio as a predictive biomarker for response to high dose interleukin-2 in patients with renal cell carcinoma. BMC Urol. 2017;17:1.

[49] Pawłowski R1, Mühl SM, Sulser T, Krek W, Moch $\mathrm{H}$, Schraml P. Loss of PBRM1 expression is associated with renal cell carcinoma progression. Int J Cancer. 2013;132:E11-7.

[50] van der Mijn JC, Mier JW, Broxterman HJ, Verheul HM. Predictive biomarkers in renal cell cancer: Insights in drug resistance mechanisms. Drug Resist Updat. 2014;17:77-88. 